\title{
Cerebral Metabolism in the Newborn Lamb with Polycythemia
}

\author{
TED S. ROSENKRANTZ, ANTHONY F. PHILIPPS, PETER S. SKRZYPCZAK, AND \\ JOHN R. RAYE \\ University of Connecticut Health Center, Department of Pediatrics, Division of Neonatology, \\ Farmington, Connecticut 06032
}

\begin{abstract}
Infants with polycythemia and hyperviscosity are known to have a reduced cerebral blood flow. Eight newborn lambs were studied to determine what effect the reduction in cerebral blood flow might have on the cerebral delivery and uptake of oxygen, glucose, lactate, pyruvate, $\beta$-hydroxybutyrate, and acetoacetate. Measurements of cerebral blood flow, hematocrit, blood viscosity as well as delivery and uptake of the forementioned substrates were made during a control period and at 60,180 , and $300 \mathrm{~min}$ after an exchange transfusion with packed newborn red blood cells was performed to increase the hematocrit. Sixty min after the exchange transfusion, cerebral blood flow fell while cerebral oxygen delivery and uptake were stable. Although arterial glucose concentration remained unchanged, there was a significant fall in cerebral glucose delivery. At $180 \mathrm{~min}$ after the exchange transfusion, the arterial glucose concentration fell from 90 to $70 \mathrm{mg} / \mathbf{1 0 0}$ $\mathrm{ml}$ causing the cerebral glucose delivery to further decrease. This resulted in a significant fall in the cerebral glucose uptake and glucose:oxygen quotient. At $\mathbf{3 0 0} \mathrm{min}$ arterial glucose concentration remained low but a rise in cerebral blood flow resulted in a small increase in the cerebral glucose delivery and consequently the cerebral glucose uptake and glucose:oxygen quotient returned to normal. We conclude that polycythemia results in a decrease in cerebral glucose delivery and uptake during normoglycemia. (Pediatr Res 23: 329-333, 1988)
\end{abstract}

\section{Abbreviations}

CBF, cerebral blood flow

PRBC, packed red blood cells

$\mathrm{G} / \mathrm{O}_{2}$, glucose/oxygen quotient

cmp, counts/min

Polycythemia and hyperviscosity occur in 3-5\% of all newborn infants and as many as $40 \%$ of affected infants have long-term neurologic and developmental sequelae (1-3). The etiology of the central nervous system damage is not known. It had been postulated that the cerebral blood flow of these infants was reduced secondary to an elevation in blood viscosity, resulting in cerebral ischemia and hypoxia $(4,5)$. We have previously shown in the newborn lamb with polycythemia that the reduction in cerebral blood flow is due to an associated elevation in arterial

Received July 24, 1987; accepted November 16, 1987.

Correspondence, Dr. T. S. Rosenkrantz, University of Connecticut Health Center, Department of Pediatrics, Farmington Avenue, Farmington, CT 06032

Supported by grants from The Charles $\mathrm{H}$. Hood Foundation and NIH Grant DK 26067. oxygen content, not viscosity, and that oxygen delivery to the brain is normal (6).

In the study of Black et al. (3) infants.with polycythemia and concurrent hypoglycemia were at the highest risk for poor outcome. This led to consideration of whether the delivery of cerebral metabolic fuels, particularly glucose, might be limited by the reduction of cerebral blood flow that occurs in the polycythemic state and might the reduced substrate delivery adversely affect substrate uptake by the brain.

Glucose, normally the primary cerebral fuel, is present in the water phase of blood and therefore exists primarily in the plasma portion of the blood as the red blood cell water content is relatively low due to the corpuscular hemoglobin content. In the infant with polycythemia, the red cell volume is increased whereas the plasma fraction of the blood is reduced. A reduction in the plasma fraction in combination with a reduction in cerebral blood flow would be expected to result in a lowered cerebral plasma flow. This would mean that at a similar plasma glucose concentration, cerebral glucose delivery would be greatly reduced in the infant with polycythemia as compared to an infant with a normal hematocrit. Additionally, the cerebral delivery of other metabolic substrates might also be similarly restricted. The following study was designed to test these hypotheses.

\section{METHODS}

Surgical. Eight newborn lambs were catheterized under ketamine $(8 \mathrm{mg} / \mathrm{kg}$ intramuscularly) and pentobarbital (16 mg intravenously) anesthesia with local infiltration with $1 \%$ lidocaine solution. Tygon catheters (ID $1.02 \mathrm{~mm}$, Norton Co., Akron, $\mathrm{OH})$ were placed into the left ventricle of the heart via the right axillary artery, aortic root via the left axillary artery, abdominal aorta via the right femoral artery, and inferior vena cava via the right femoral vein. A polyvinyl catheter (ID $0.87 \mathrm{~mm}$, Bolab, Inc., Lake Havasu, AZ) was inserted into the superior sagittal sinus and advanced $1 \mathrm{~cm}$. Catheter placement was confirmed at autopsy.

Postoperatively, the animals were returned to their mothers and allowed a 48-h recovery period before study. Postnatal age and weight at the time of surgery were $4.8 \pm 0.8$ days (mean \pm $\mathrm{SE}$ ) and $4.1 \pm 0.2 \mathrm{~kg}$, respectively.

Physiologic measurements. Blood pressure and heart rate were measured using a physiologic pressure transducer (Statham Laboratories, Hato Rey, PR) and recorded on a Hewlett Packard polygraph (Hewlett Packard, Waltham, MA). Arterial blood gases and $\mathrm{pH}$ were analyzed using the Corning Blood Gas Analyzer 178 (Corning Scientific Instruments, Medford, MA). Oxygen content in whole blood was measured with a Lex- $\mathrm{O}_{2}$-Con (Lexington Instruments Corp., Waltham, MA) (7). Hematocrit was measured in duplicate using a microcentrifuge. Whole blood viscosity was determined using a Wells-Brookfield Cone/Plate 
Viscometer at shear rates of 5.7, 11.50, 23.0, 46.0, and $115.0 \mathrm{~s}^{-1}$. Similar changes were observed at all shear rates; therefore, only viscosity values at a shear rate of $46.0 \mathrm{~s}^{-1}$ are presented herein. Whole blood glucose was measured using the glucose oxidase method (7). Lactate, pyruvate, $\beta$-hydroxybutyrate, and acetoacetate were measured enzymatically $(8,9)$. Insulin concentration was determined by a modification of the double antibody immunoassay technique (10). Ovine insulin standards were kindly supplied by Mary Root, Ph.D. (Eli Lilly and Co., Indianapolis, IN).

Blood flow determinations. CBF was measured using radionuclide-labeled microspheres ( $15 \pm 5 \mu \mathrm{m}$ diameter, New England Nuclear, Boston, MA) as described by Heymann et al. (11). Microspheres were labeled with ${ }^{57} \mathrm{Co},{ }^{113} \mathrm{Sn},{ }^{95} \mathrm{Nb}$, or ${ }^{46} \mathrm{Sc}$. For each flow determination, $8.5 \times 10^{5}$ microspheres, suspended in a $1 \mathrm{ml}$ solution of $10 \%$ dextran and $0.01 \%$ Tween 80 , were injected into the left ventricle over a 30 -s period. A reference sample of blood was withdrawn from the aortic root for a 2-min period at a constant rate of $1.94 \mathrm{ml} / \mathrm{min}$, starting $25 \mathrm{~s}$ before the injection of microspheres. After fixation in $10 \%$ formalin, the brain was sectioned into $0.2-1.5 \mathrm{~g}$ pieces. Radioactivity of the brain sections and reference blood samples were measured with a gamma counter (Searle Analytic, Inc., Des Plaines, IL) and multi-channel analyzer (Nuclear Data, Inc., Schaumburg, IL). The following formula was used to calculate tissue blood flow.

$\frac{\mathrm{cmp} \text { of microspheres in tissue }}{\mathrm{cmp} \text { of microspheres in reference sample }} \times \begin{array}{r}\text { rate of withdrawal }= \\ \text { tissue blood flow. }\end{array}$

Brain blood flow was expressed as $\mathrm{ml} / \mathrm{min} / 100 \mathrm{~g}$ wet weight.

Study design. Lambs were separated from their mothers on the morning of the study, brought to the laboratory and lightly restrained. The animals were then allowed to acclimate for a $60-$ min period. At the end of that period, measurements were made of heart rate and mean arterial blood pressure. Arterial blood was sampled for blood gases and $\mathrm{pH}$, hematocrit and viscosity as well as for oxygen content and the concentrations of glucose, lactate, pyruvate, $\beta$-hydroxybutyrate, acetoacetate, and insulin. Sagittal sinus venous blood was also obtained for oxygen content and the concentrations of glucose, lactate, pyruvate, $\beta$-hydroxybutyrate, and acetoacetate. Lastly, an arterial sample of blood was drawn from the aortic root during the injection of radionuclide-labeled microspheres for determination of CBF. After these measurements, an exchange transfusion was performed over $60 \mathrm{~min}$ in each lamb to raise the hematocrit and viscosity. Age-matched newborn PRBC $(60 \mathrm{ml} / \mathrm{kg})$ were used. The cells had been previously stored in citrate-phosphate-dextrose blood bags, washed twice with $0.9 \%$ saline solution, and packed just before the study. The hematocrit of the PRBC was $90-95 \%$. The previous physiologic and metabolic measurements were repeated 60,180 , and 300 min after the exchange transfusion. At the end of the study the lambs were killed and the brains removed. The brains were weighed and preserved in $10 \%$ formalin for later measurement of radioactivity and calculation of $\mathrm{CBF}$.

Data analysis. Substrate delivery was calculated as the product of the arterial blood concentration and CBF. Substrate uptake or production was calculated as the product of $\mathrm{CBF}$ and the arterial-venous (sagittal sinus) concentration difference of the substrate.

The cerebral $\mathrm{G} / \mathrm{O}_{2}$ was calculated by the following formula:

$$
\text { cerebral } \mathrm{G} / \mathrm{O}_{2}=\frac{\begin{array}{c}
6 \times \text { cerebral glucose uptake } \\
(\mu \mathrm{mol} / \mathrm{min} / 100 \mathrm{~g})
\end{array}}{\begin{array}{c}
\text { cerebral oxygen uptake } \\
(\mu \mathrm{mol} / \mathrm{min} / 100 \mathrm{~g}) .
\end{array}}
$$

Substrate extraction (\%) was calculated as follows:

$$
\text { cerebral substrate extraction }=\frac{\begin{array}{c}
\text { cerebral substrate } \\
\text { cerebral substrate } \\
\text { delivery }
\end{array}}{\begin{array}{c}
\text { uptake } \\
\text { dela }
\end{array}} \times 100 \text {. }
$$

Data were analyzed using one-way analyses of variance for repeated measures, Student's $t$ tests and linear regression analyses.

\section{RESULTS}

Exchange transfusions were performed without difficulty in each of the eight newborn lambs. The heart rate decreased after the exchange transfusion from $241 \pm 13 \mathrm{bpm}$ (mean $\pm \mathrm{SE}$ ) to $189 \pm 28(p<0.01)$ and then remained stable throughout the remainder of the study (Table 1 ). The mean arterial blood pressure was $79 \pm 4 \mathrm{~mm} \mathrm{Hg}$ during the control period and was stable throughout. The $\mathrm{pO}_{2}$ was $83 \pm 3 \mathrm{~mm} \mathrm{Hg}, \mathrm{pCO}_{2}$ was $38 \pm$ $1 \mathrm{~mm} \mathrm{Hg}$, and the $\mathrm{pH}$ was $7.46 \pm 0.01$ at the start of this study. The $\mathrm{pO}_{2}$ was unchanged, whereas the $\mathrm{pCO}_{2}$ and $\mathrm{pH}$ both decreased after the exchange transfusion to $33 \pm 1$ and $7.39 \pm 0.1$, respectively. The values were then stable at these levels for the remainder of the study. The hematocrit rose from $27 \pm 2$ to 51 $\pm 3 \%, 60 \mathrm{~min}$ after the exchange transfusion and was $46 \pm 2 \%$, $300 \mathrm{~min}$ after the transfusion $(p<0.001)$ (Fig. 1). There was a corresponding rise in viscosity from $3.1 \pm 0.3$ centipoise (shear rate $\left.=46 \mathrm{~s}^{-1}\right)$ to $6.6 \pm 1.1(p<0.001)$. This represents an increase of more than $3 \mathrm{SD}$ from the control value. Arterial oxygen content rose from $14.3 \pm 0.7$ to $24.6 \pm 1.1$ vol\% $60 \mathrm{~min}$ postexchange transfusion $(p<0.001)$ and remained at that level. There was a similar increase in the cerebral arteriovenous difference of the blood oxygen content (Table 2). Conversely, cerebral blood flow was initially $106.5 \pm 2.7 \mathrm{ml} / \mathrm{min} / 100 \mathrm{~g}$ and fell to $58.1 \pm 4.8,68.9 \pm 4.9$, and $78.6 \pm 7.3 \mathrm{ml} / \mathrm{min} / 100 \mathrm{~g}$ at 60,180 , and $300 \mathrm{~min}$ after the exchange transfusion, respectively. As a result of these changes in oxygen content and cerebral blood flow, the cerebral oxygen uptake did not change from a control value of $7.6 \pm 0.1 \mathrm{ml} / \mathrm{min} / 100 \mathrm{~g}$ tissue for the duration of the study.

The initial values for arterial whole blood glucose concentration and cerebral glucose delivery were $101.3 \pm 7.5 \mathrm{mg} / 100 \mathrm{ml}$ and $102.6 \pm 10.5 \mathrm{mg} / \mathrm{min} / 100 \mathrm{~g}$, respectively (Fig. 2). At $60 \mathrm{~min}$ postexchange transfusion, arterial whole blood glucose concentration was unchanged but cerebral glucose delivery fell to 54.2

Table 1. Heart rate, mean arterial blood pressure, $\mathrm{PO}_{2}, \mathrm{pCO}_{2}$, and $p H$ during control and study periods (mean $\left.\pm S E\right)$

\begin{tabular}{lcccc}
\hline & \multicolumn{4}{c}{$\begin{array}{c}\text { Time postexchange } \\
\text { transfusion (min) }\end{array}$} \\
\cline { 2 - 4 } & Control & 60 & 180 & 300 \\
\hline Heart rate (beats/min) & $241 \pm 13$ & $189 \pm 10^{*}$ & $189 \pm 6^{*}$ & $189 \pm 10^{*}$ \\
Mean arterial blood pressure $(\mathrm{mm} \mathrm{Hg})$ & $79 \pm 4$ & $84 \pm 5$ & $79 \pm 4$ & $77 \pm 5$ \\
$\mathrm{pO}_{2}(\mathrm{~mm} \mathrm{Hg})$ & $83 \pm 3$ & $79 \pm 4$ & $84 \pm 4$ & $76 \pm 3$ \\
$\mathrm{pCO}_{2}(\mathrm{~mm} \mathrm{Hg})$ & $38 \pm 1$ & $33 \pm 1 \dagger$ & $32 \pm 2 \dagger$ & $34 \pm 1 \dagger$ \\
$\mathrm{pH}$ & $7.46 \pm 0.01$ & $7.39 \pm 0.01^{*}$ & $7.38 \pm 0.02 \dagger$ & $7.37 \pm 0.02^{*}$ \\
\hline
\end{tabular}

$* p<0.01$ versus control.

$\dagger p<0.05$ versus control. 
$\pm 8.0 \mathrm{mg} / \mathrm{min} / 100 \mathrm{~g}(53 \%$ of the control value $)(p<0.01)$. Due to an increase in cerebral glucose extraction from $10.6 \pm 1.5$ to $19.5 \pm 3.0 \%(p<0.02)$, cerebral glucose uptake was unchanged. At $180 \mathrm{~min}$ postexchange transfusion, the glucose concentration in arterial blood fell to $70.1 \pm 5.2 \mathrm{mg} / 100 \mathrm{ml}(p<0.01)$, decreasing the cerebral glucose delivery to its lowest value during the study, $47.4 \pm 5.9 \mathrm{mg} / 100 \mathrm{~g} / \mathrm{min}$ (46\% of the control value) $(p<0.001)$. Cerebral glucose extraction did not increase any further $(18.2 \pm 2.6 \%)$ and cerebral glucose uptake decreased at this time $(p<0.05)$. At $300 \mathrm{~min}$ after the exchange transfusion, the arterial glucose concentration remained low but there was a small increase in the cerebral blood flow. As a result, the cerebral glucose delivery returned to the level observed at $60 \mathrm{~min}$ postexchange transfusion. Cerebral glucose extraction remained elevated, $19.2 \pm 4.0 \%$. This was associated with a return of the cerebral glucose uptake to control levels.

To examine whether the measured cerebral uptake of glucose could totally provide for the aerobic metabolic demands of the brain and to control for variation in the cerebral metabolic rate, cerebral $\mathrm{G} / \mathrm{O}_{2}$ were calculated and are shown in Table 3. This illustrates that at 180 min postexchange transfusion, when cerebral glucose delivery was at its lowest point, there was a significant decrease in the $\mathrm{G} / \mathrm{O}_{2}$.

Regression analysis was used to further analyze the relationship between arterial glucose concentration, cerebral glucose delivery, and uptake. Arterial glucose concentration, cerebral glucose delivery, and uptake data for the entire study were grouped for these analyses. Between cerebral glucose delivery rates of 40-150 $\mathrm{mg} / \mathrm{min} / 100 \mathrm{~g}$, the cerebral glucose uptake was relatively con-

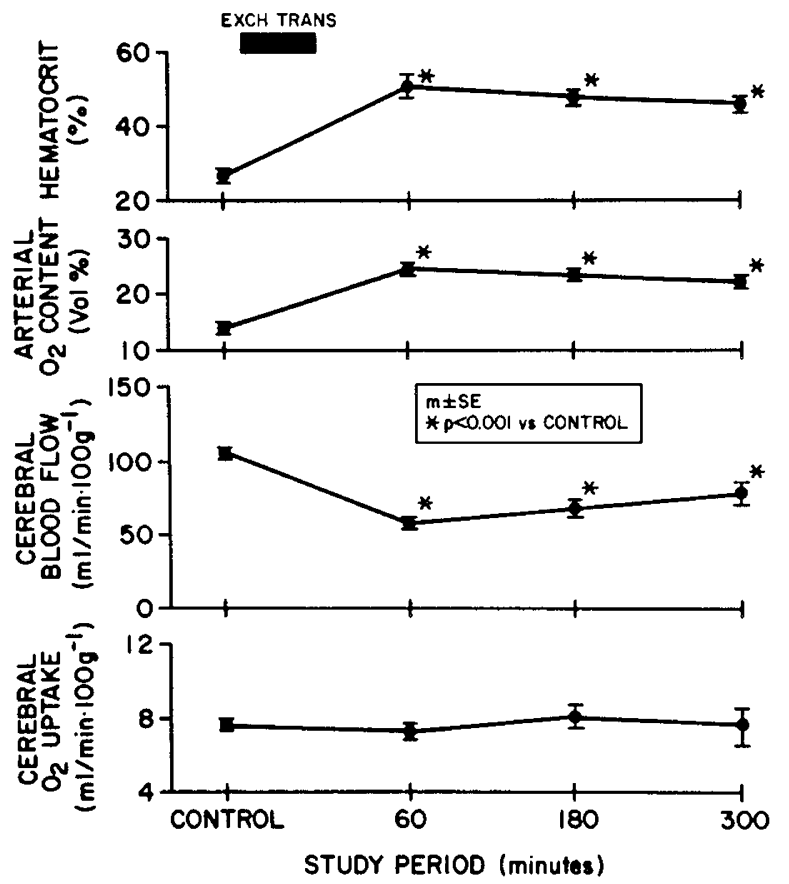

zFig. 1. Values for hematocrit, arterial oxygen content, CBF, and cerebral oxygen uptake during control and study periods. stant (Table 4). At cerebral glucose delivery rates below $40 \mathrm{mg}$ / $\mathrm{min} / 100 \mathrm{~g}$, the cerebral glucose uptake fell to $7.3 \pm 1.4 \mathrm{mg} / \mathrm{min} /$ $100 \mathrm{~g}(p<0.05)$.

Cerebral glucose uptake was also examined as a function of the arterial glucose concentration. The range of arterial glucose concentrations was 38 to $135 \mathrm{mg} / 100 \mathrm{ml}$. No relationship was found between the arterial glucose concentration and cerebral glucose uptake.

Table 5 shows the control and postexchange transfusion values for lactate, pyruvate, $\beta$-hydroxybutyrate, and acetoacetate uptake/production. As observed, there were no significant changes from baseline during the study. Regression analysis revealed that cerebral delivery of these substrates was linearly correlated to cerebral blood flow $(p<0.001)$. Therefore, as CBF fell at 60 , 180 , and $300 \mathrm{~min}$, the delivery of these substrates was restricted. The control plasma insulin concentration was $84.4 \pm 9.1 \mu \mathrm{u} / \mathrm{ml}$ and was unchanged during the study.

\section{DISCUSSION}

It is well documented that infants with polycythemia and hyperviscosity are at significant risk for developmental and neurologic sequelae $(3,4,12-14)$. Previous work has shown that while the cerebral blood flow of infants with polycythemia is reduced, the concomitant elevation in arterial oxygen content results in a normal delivery of oxygen at the capillary level (6). Herein we have further documented that due to an increase in the arteriovenous difference of the blood oxygen content, the uptake of oxygen by the brain during periods of polycythemia

Table 2. Arterial oxygen content $\left(\mathrm{CaO}_{2}\right)$ and cerebral arterial venous (sagittal sinus) difference in oxygen content during control and study periods (mean $\pm S E)$

Time postexchange transfusion

(min)

\begin{tabular}{lcccc} 
& Control & 60 & 180 & 300 \\
\hline $\mathrm{CaO}_{2}(\mathrm{vol} \%)$ & $14.3 \pm 0.7$ & $24.6 \pm 1.1^{*}$ & $23.4 \pm 0.9^{*}$ & $22.1 \pm 0.7$ \\
${\mathrm{Cerebral} \mathrm{Ca}-\mathrm{vO}_{2}(\mathrm{vol} \%)}^{7.2 \pm 0.2}$ & $13.1 \pm 1.0^{*}$ & $11.9 \pm 0.8^{*}$ & $10.0 \pm 0.4^{*}$ \\
\hline
\end{tabular}

$* p<0.001$ versus control. 
and hyperviscosity is similar to that found when the hematocrit is normal. Therefore, it is unlikely that neurologic damage seen in infants with polycythemia is related to brain ischemia/hypoxia due to the increased hematocrit and viscosity and the associated reduction in cerebral blood flow:

Glucose appears to be an essential substrate for normal cerebral function. The neurologic abnormalities and cerebral metabolic dysfunction that accompany hypoglycemia and cerebral glucopenia are well documented (15-17). In studies of newborn and adult animals as well as adult humans, cerebral blood flow has been shown to be unaffected by changes in blood glucose concentration. That is, there is no compensatory increase in cerebral blood flow when the blood concentration of glucose is low (15, $18,19)$. Therefore, when the arterial blood glucose concentration decreases, glucose delivery decreases proportionally. Under normal conditions, the newborn and adult brain is able to extract the necessary amount of glucose for normal cerebral function as long as the plasma glucose concentration is $>30 \mathrm{mg} / 100 \mathrm{ml}(15$, $18,20)$. As the glucose concentration and, therefore, cerebral glucose delivery decreases below this point, there is an acute reduction in cerebral uptake of glucose (15).

If the cerebral uptake of glucose is a function of the plasma or blood glucose concentration, independent of changes in cerebral blood flow, then infants with polycythemia should have adequate uptake of glucose to meet the oxidative metabolic demands of the brain as long as the glucose concentration is normal. If, on the other hand, cerebral glucose uptake is dependent on total

Table 3. $G / \mathrm{O}_{2}$ during control and study periods (mean $\pm S E$ )

\begin{tabular}{lcccc}
\hline \multicolumn{5}{c}{ Time postexchange transfusion } \\
& \multicolumn{5}{c}{$(\mathrm{min})$} \\
\cline { 2 - 5 } & Control & 60 & 180 & 300 \\
\hline $\mathrm{G} / \mathrm{O}_{2}$ & $1.08 \pm 0.15$ & $1.10 \pm 0.17$ & $0.73 \pm 0.10^{*}$ & $0.91 \pm 0.14$ \\
\hline$* p<0.05$ compared to all other periods.
\end{tabular}

Table 4. Relationships between cerebral glucose delivery and cerebral glucose uptake (mean $\pm S E$ )

\begin{tabular}{lccc}
\hline & \multicolumn{3}{c}{$\begin{array}{c}\text { Cerebral glucose delivery } \\
(\mathrm{mg} / \mathrm{min} / 100 \mathrm{~g})\end{array}$} \\
\cline { 2 - 4 } & $80-150$ & $40-79$ & $0-39$ \\
\hline $\begin{array}{l}\text { Cerebral glucose uptake } \\
(\mathrm{mg} / \mathrm{min} / 100 \mathrm{~g})\end{array}$ & $\begin{array}{c}10.7 \pm 1.3 \\
(n=6) \dagger\end{array}$ & $\begin{array}{c}9.7 \pm 1.2 \\
(n=16)\end{array}$ & $\begin{array}{c}7.3 \pm 1.4^{*} \\
(n=7)\end{array}$ \\
\hline
\end{tabular}

$* p<0.05$.

$\uparrow$ No. of individual sets of measurements. cerebral glucose delivery ( $\mathrm{CBF} \times$ arterial glucose concentration), it would be expected that in the polycythemic model, uptake might be diminished during periods of normal plasma glucose concentration due to the reduction in cerebral glucose delivery. The diminution in delivery would be the result of a reduction in the total amount of circulating glucose due to the decrease in plasma space and a reduction in CBF. In fact, this appeared to be the case $180 \mathrm{~min}$ after the exchange transfusion. At this time, despite a normal arterial whole blood glucose concentration, cerebral glucose delivery was at its minimum and there was an acute reduction in cerebral glucose uptake. The $\mathrm{G} / \mathrm{O}_{2}$ at that time would suggest that at a minimum, $29 \%$ of the cerebral oxidative requirements was unmet by the measured rate of cerebral glucose uptake. At $300 \mathrm{~min}$, the arterial glucose concentration was unchanged but due to a minor increase in $\mathrm{CBF}$, there was an increase in cerebral glucose delivery and the cerebral glucose uptake returned to normal. The above data may be interpreted to indicate that cerebral glucose delivery rather than blood glucose concentration is the determining factor in cerebral glucose uptake. It also suggests that the brains of infants with polycythemia may become glucopenic during periods when the blood glucose concentration is significantly above values traditionally considered to be low.

Analysis of the relationship of arterial glucose concentration, cerebral glucose delivery, and cerebral glucose uptake values for the entire study confirms the above conclusion. That is, the cerebral glucose uptake did not vary with changes in arterial glucose concentration but was strongly correlated to changes in cerebral glucose delivery.

The cerebral oxygen uptake was unchanged throughout the study including periods of time when cerebral glucose uptake was reduced as reflected by $\mathrm{a}_{2} / \mathrm{O}$ of less than 1.00 . This finding would suggest cerebral utilization of alternate substrates. While there were not significant changes in the cerebral uptake of pyruvate, $\beta$-hydroxybutyrate, or acetoacetate, there was a trend toward increased cerebral uptake of lactate when cerebral glucose uptake was at its lowest point. Additionally, the brains may have increased the uptake and catabolism of substrates from the blood or cerebral stores that were not measured herein, such as amino acids. This phenomenon has been demonstrated by other investigators $(16,21-24)$.

Black et al. (3) found that concurrent hypoglycemia placed infants with polycythemia at the highest risk for poor neurologic outcome. The finding of decreased cerebral glucose delivery and use during a period of normoglycemia in the lamb model might lead to speculation that some of the neurologic sequelae observed in human infants with polycythemia may be due to cerebral glucopenia associated with a normal plasma or blood glucose concentration. At the same time, the finding of an unchanging

Table 5. Arterial concentration and cerebral uptake/production of lactate, pyruvate, $\beta$-hydroxybutyrate, and acetoacetate during control and study periods (mean $\pm S E$ )

\begin{tabular}{llcccc}
\hline & & \multicolumn{4}{c}{$\begin{array}{c}\text { Time postexchange } \\
\text { transfusion (min) }\end{array}$} \\
\cline { 3 - 6 } & & Control & 60 & 180 & 300 \\
\hline Lactate & Conc* & $1.73 \pm 0.27$ & $1.37 \pm 0.17$ & $1.34 \pm 0.13$ & $1.31 \pm 0.22$ \\
& $\mathrm{CM} \dagger$ & $-0.006 \pm 0.008$ & $-0.010 \pm 0.009$ & $+0.002 \pm 0.003$ & $-0.003 \pm 0.004$ \\
Pyruvate & Conc & $0.113 \pm 0.022$ & $0.107 \pm 0.019$ & $0.098 \pm 0.010$ & $0.068 \pm 0.013$ \\
& CM & 0 & 0 & 0 & 0 \\
B-hydroxybutrate & Conc & $0.304 \pm 0.045$ & $0.205 \pm 0.016$ & $0.139 \pm 0.026 \pm$ & $0.160 \pm 0.037 \S$ \\
& CM & $0.002 \pm 0.002$ & 0 & $-0.002 \pm 002$ & $-0.002 \pm 002$ \\
Acetoacetate & Conc & $0.037 \pm 0.006$ & $0.019 \pm 0.005 \S$ & $0.023 \pm 0.004$ & $0.031 \pm 0.006$ \\
& $\mathrm{CM}$ & 0 & 0 & 0 & 0 \\
\hline
\end{tabular}

* Blood substrate concentration in $\mathrm{mM} /$ liter.

$\dagger$ Cerebral substrate uptake $(+)$ or production $(-)$ in $\mathrm{mM} / \mathrm{min} / 100 \mathrm{~g}$.

$\ddagger p<0.01$ compared to control.

$\S p<0.05$ compared to control. 
cerebral oxygen uptake suggests that the brain of the infant with polycythemia may be able to use alternate substrates and maintain normal function despite a deficiency in cerebral glucose availability. Further investigation of cerebral metabolism and function in neonatal polycythemia will be necessary to clarify the role of cerebral glucopenia in the poor neurologic outcome of affected infants.

In summary, polycythemia did not alter cerebral oxygen delivery or uptake in the chronically catheterized newborn lamb. However, significant reductions in cerebral glucose uptake did occur in lambs with polycythemia while normoglycemic. This finding may be interpreted to indicate that cerebral glucose use in the newborn lamb is not dependent solely on the arterial blood glucose concentration but rather is dependent on cerebral glucose delivery, a function of plasma glucose concentration, plasma volume, and CBF.

\section{REFERENCES}

1. Wirth FH, Goldberg KE, Lubchenco LO 1979 Neonatal hyperviscosity. I. Incidence Pediatrics 63:833-836

2. Steven K, Wirth FH 1980 Incidence of neonatal hyperviscosity at sea level. J Pediatr 97:118-1 19

3. Black VD, Lubchenco LO, Luckey DW, Koops BL, McGuiness GA, Powell DP, Tomlinson AL 1982 Developmental and neurologic sequelae of neonatal hyperviscosity syndrome. Pediatrics $69: 426-431$

4. Wood JL 1959 Plethora in the newborn infant associated with cyanosis and convulsions. J Pediatr 54:143-151

5. Gross GP, Hathaway WE, McGaughey HR 1973 Hyperviscosity in the neonate. J Pediatr 82:1004-1012

6. Rosenkrantz TS, Stonestreet BS, Hansen NB, Nowicki P, Oh W 1984 Cerebral blood flow in the newborn lamb with polycythemia and hyperviscosity. $J$ Pediatr 104:276-280

7. Sigma Tech Bulletin 5101976

8. Olsen C 1971 An enzymatic fluorimetric micromethod for determination of acetoacetate, $\beta$-hydroxybutyrate, pyruvate and lactate. Clin Chima Acta 33:293-300
9. Burgmeyer NY 1974 Methods of Enzymatic Analysis, Vol 4. Verlag Chemie Weinheim Academic Press, New York, p 1679

10. Philipps AF, Carson BC, Meschia G, Battaglia FC 1978 Insulin secretion in fetal and newborn sheep. Am J Physiol 235:E467-E474

11. Heymann MA, Payne BD, Hoffman JIE, Rudolph AM 1977 Blood flow measurements with radionuclide-labeled particles. Prog Cardiovasc Dis 20:55-79

12. Amit M, Camfield PR 1980 Neonatal polycythemia causing multiple cerebral infarcts. Arch Neurol 37:109-110

13. Van der Elst CW, Molteno CD, Malan AF, de V Hesse H 1980 The management of polycythemia in the newborn infant. Early Hum Dev 4:393-403

14. Goldberg K, Wirth FH, Hathaway WE, Guggenheim MA, Murphy JR, Braithwaite WR, Lubchenco LO 1982 Neonatal hyperviscosity. II. Effect of partial plasma exchange transfusion. Pediatrics 64:419-425

15. Kety SS, Woodford RB, Harmel MH, Freyhan FH, Appel KE, Schmidt CF 1948 Cerebral blood flow and metabolism in schizophrenia. Am J Psychiat 104:765-770

16. Gardiner RM 1980 The effects of hypoglycaemia on cerebral blood flow and metabolism in the new-born calf. $\mathbf{J}$ Physiol 298:37-51

17. Koivisto M, Blanco-Sequeiros M, Krause V 1972 Neonatal symptomatic and asymptomatic hypoglycaemia: a follow-up study of 151 children. Dev Med Child Neurol 14:603-614

18. Mcllwain H, Bachelard HS 1985 Biochemistry and the Central Nervous System. Churchill-Livingstone, Edinburgh, pp 10, 13

19. Hernandez MJ, Vannucci RC, Salcedo A, Brennan RW 1980 Cerebral blood flow and metabolism during hypoglycemia in newborn dogs. $\mathbf{J}$ Neurochem 35:622-628

20. Cornblath M, Schwartz R 1976 Disorders of Carbohydrate Metabolism in Infancy. WB Saunders Co., Philadelphia, pp 155-217

21. Hellman J, Vannucci RC, Nardis EE 1982 Blood-brain barrier permeability to lactic acid in newborn dogs: lactate and cerebral metabolic fuel. Pediatr Res $16: 40-44$

22. Thurston JH, Hauhart RE, Schiro JA 1983 Lactate reverses insulin-induced hypoglycemic stupor in suckling-weanling mice: biochemical correlates in blood, liver and brain. J Cereb Blood Flow Metab 3:498-506

23. Lewis LD, Ljunggren B, Norberg K, Siesjo BK 1974 Changes in carbohydrate substrates, amino acids and ammonia in the brain during insulin-induced hypoglycemia. J Neurochem 23:659-671

24. Goldberg ND, Passonneau JV, Lowry OH 1966 Effects of changes in brain metabolism on the levels of citric acid cycle intermediates. J Biol Chem 241:3997-4003 